\title{
Does Maxillary Retrusion in Skeletal Class III Malocclusion Affect the Perception of Facial Aesthetics? Evaluation of Different Groups
}

\author{
Selene Barone ${ }^{1}{ }^{1}$, Fiorella Averta ${ }^{1}$, Danila Muraca ${ }^{1}$, Federica Diodati ${ }^{1}$, Francesco Bennardo ${ }^{1}$, \\ Alessandro Antonelli ${ }^{1}$ (D) and Amerigo Giudice ${ }^{1,2, *(D)}$ \\ 1 Department of Health Sciences, School of Dentistry, Magna Graecia University of Catanzaro, \\ 88100 Catanzaro, Italy; barone.selene19@gmail.com (S.B.); fiore.averta@gmail.com (F.A.); \\ muracadanila@gmail.com (D.M.); fefediodati@gmail.com (F.D.); fbennardo92@gmail.com (F.B.); \\ antonellicz@gmail.com (A.A.) \\ 2 Department of Health Sciences, Maxillofacial Surgery Division, Magna Graecia University of Catanzaro, \\ 88100 Catanzaro, Italy \\ * Correspondence: a.giudice@unicz.it
}

Citation: Barone, S.; Averta, F.; Muraca, D.; Diodati, F.; Bennardo, F.; Antonelli, A.; Giudice, A. Does Maxillary Retrusion in Skeletal Class III Malocclusion Affect the Perception of Facial Aesthetics? Evaluation of Different Groups. Oral 2021, 1 , 216-223. https://doi.org/10.3390/ oral1030021

Academic Editors:

Giuseppina Campisi and

Marco Mascitti

Received: 10 June 2021

Accepted: 13 July 2021

Published: 15 July 2021

Publisher's Note: MDPI stays neutral with regard to jurisdictional claims in published maps and institutional affiliations.

Copyright: (c) 2021 by the authors. Licensee MDPI, Basel, Switzerland. This article is an open access article distributed under the terms and conditions of the Creative Commons Attribution (CC BY) license (https:// creativecommons.org/licenses/by/ $4.0 /)$.

\begin{abstract}
Background: The perception of facial aesthetics is a complex topic due to its subjective nature and it can be influenced by several factors. The purpose of this study was to compare the perception of general dentists, orthodontists, maxillofacial surgeons, and lay people by evaluating facial aesthetics in skeletal class III patients, especially for maxillary sagittal position. Methods: A survey consisting of three sets of pre-treatment photographs of four dysmorphic patients was used. The questionnaire was submitted to a total of 200 participants divided into the following four subgroups: general dentists, orthodontists, maxillofacial surgeons, and lay people. Their opinion on facial disharmony, sagittal position of the jaws, asymmetry of the chin, projection of the cheekbone area, and lip aesthetics was recorded. Results: Significant differences were found between experts and non-experts in the perception of the maxillary position, asymmetry of the chin and zygomatic area $(p<0.01)$. No statistically significant differences were found among the groups in the perception of mandibular position and lip aesthetics. Conclusion: The respondents with a medical or dental background perceived the presence of maxillary retrusion more than others. Only orthodontists and maxillofacial surgeons have recognized an alteration of the middle facial third as a greater component of skeletal class III malocclusion.
\end{abstract}

Keywords: angle class III malocclusion; facial components; aesthetics; maxillary retrusion; laypeople; orthodontists

\section{Introduction}

Dentofacial deformities determine an alteration of the maxillomandibular complex, often causing functional and psychological problems for the patient [1]. In order to obtain a stable occlusion and a harmonious facial profile, both orthodontic and orthognathic treatments are necessary [2]. Although the planning of an orthodontic/orthognathic treatment is strictly dependent on a good occlusal relationship, to date, the aesthetic assessment plays a fundamental role, analyzing the patient's soft tissues as the main component for a satisfactory result [3]. However, facial attractiveness is not based on well-defined parameters, but it is significantly influenced by the subjectiveness of aesthetics, leading to different opinions [4]. Age, gender, level of education, occupation, and ethnicity are subjective elements affecting the aesthetic facial evaluation. For this reason, the facial perception could be different among laypeople, patients, and clinicians, with a multifactorial point of view [5].

Severe skeletal class III malocclusion is the most common facial deformity requiring orthognathic surgery [6,7]. This type of malocclusion can be determined by a mandibu- 
lar growth excess or a maxillary growth deficiency, or an alteration of both maxilla and mandible [8]. Ellis and McNamara showed that the most common skeletal class III malocclusion was caused by a combination of mandibular protrusion and maxillary retrusion [9]. However, in these patients, a prominent mandibular profile is usually recognized, misunderstanding a decreased sagittal projection of the maxilla that interferes with facial harmony [10]. In many cases, patients showed a facial asymmetry in addition to the sagittal discrepancy, worsening their aesthetic aspect [11]. Several authors showed significant difference in the assessment of facial perception for skeletal class III patients among dental professionals, orthodontists, oral surgeons, and laypeople $[3,12,13]$. Different opinions were recorded referring to facial profile, smile aesthetics, and soft tissue harmony $[4,14]$. However, no previous studies focused on maxillary sagittal position in skeletal class III patients, evaluating its projection on soft tissues.

The purpose of this study was to compare the perceptions of several observers analyzing the photographs of orthognathic patients. The null hypothesis was the absence of different perceptions among the groups about the altered skeletal component of the malocclusion, especially in the maxillary region. The specific aim was to compare the perceptions of orthodontists, maxillofacial surgeons, general dentist, and laypeople analyzing the photographs of patients with skeletal class III malocclusion and facial asymmetry and recording their opinion on facial disharmony, the sagittal position of the jaws, chin asymmetry, projection of the zygomatic area, and lip aesthetics.

\section{Materials and Methods}

\subsection{Study Design}

The study was designed as an observational study. The protocol and ethics followed the Declaration of Helsinki. The regional ethical review board (reference for the Magna Graecia University of Catanzaro, Catanzaro, Italy) approved the study.

\subsection{Study Sample}

In this study, a total of 200 observers were recruited and separated in the following four different subgroups: laypeople, general dentist, orthodontists, and maxillofacial surgeons. A total of 4 dysmorphic patients were selected from the database of the Unit of Oral and Maxillofacial Surgery of Magna Graecia University of Catanzaro with the following characteristics: over 20 years of old, skeletal class III malocclusion $\left(\mathrm{ANB}<0^{\circ}\right.$ ), sagittal maxillary deficiency (SNA $<80^{\circ}$ ), chin deviation from the midsagittal plane $>4 \mathrm{~mm}$, complete permanent dentition, no previous facial trauma, no cleft lip or palate, no congenital disease or facial surgical treatment.

\subsection{Data Collection Method}

Three sets of standardized pre-treatment color photographs were selected for each patient, blocking out his/her eyes to avoid identifiable information. A written informed consent with detailed information had been signed by each patient for using their photographs for the research purpose. A survey was created including the photographs in the frontal, profile, and $\frac{3}{4}$ view of each patient (Figure 1). A Nikon D5600 digital camera was used to take the photographs in standard conditions. Each photograph had the same dimensions, $11.7 \times 8.3 \mathrm{~cm}$.

Each observer completed the questionnaire. The first section included 8 questions on demographic data. The second section included 8 questions on the patients' photographs, recording facial disharmony (alteration of the middle facial third; alteration of the lower facial third; no facial alteration), the sagittal position of the jaws (retroposition, normal position, advancement), chin asymmetry (centered, right deviation, left deviation), projection of the zygomatic area (flat, normal, prominent), and lip aesthetics (retroposition of upper lip, advancement of lower lip, no lip alteration). Furthermore, each observer had to determine the level of importance for an attractive facial appearance using the following score: 1 . Not important; 2 . Discretely important; 3 . Very important. 




Figure 1. Set of three standardized facial photographs of one of the selected cases included in the questionnaire. The patients showed a skeletal class III malocclusion with skeletal asymmetry.

\subsection{Study Variables}

The primary predictor variable was the observers' occupation, dividing orthodontists, maxillofacial surgeons, generic dentists, and laypeople.

The primary outcome variable was the perception of the sagittal maxillary position compared among the four subgroups.

The secondary outcome variables were the perception of the facial disharmony, sagittal mandibular position, chin asymmetry, projection of the zygomatic area, and lip aesthetics compared among the four subgroups.

Other study variables included the observers' age, gender, and ethnic origin.

\subsection{Statistical Analysis}

Recorded data were transferred to the STATA statistical package (STATA 11, StataCorp, College Station, TX, USA). Descriptive and inferential statistical analyses were performed (frequencies and percentage for categorical data; hypothesis test). Chi-square test was used to compare the facial perceptions among the four subgroups. A $p$-value $<0.05$ was considered statistically significant.

\section{Results}

A total of 200 questionnaires were recorded, 50 for each group of participants. Table 1 reported the characteristics of the observers. Most of the participants knew the procedures of orthognathic surgery $(197 ; 98.5 \%)$, preferring orthodontic treatment as the first step $(132 ; 66 \%)$.

\subsection{Maxilla}

The perception of maxillary spatial position showed a retrusion in most of the investigated specialized categories, as follows: $78 \%$ of orthodontists, $66 \%$ of maxillofacial surgeons, and $61 \%$ of generic dentists. Less agreement was recorded for laypeople, who evaluated a maxillary retrusion in $49 \%$ of answers, a correct maxillary position in $27.5 \%$, and a maxillary advancement in $23.5 \%$. The perception of maxillary position showed a statistically significant difference among the groups $(p<0.05)$. Orthodontists and maxillofacial surgeons recognized an alteration of the middle facial third as a significative component of the skeletal class III malocclusion $(p<0.01)$. 
Table 1. Descriptive statistics of the observers' characteristics.

\begin{tabular}{cc}
\hline Observers' Characteristics & Observers' Sample (\%) \\
\hline Age & $106(53)$ \\
$20-30$ years & $50(25)$ \\
$31-40$ years & $44(22)$ \\
$>41$ years & \\
Sex & $102(51)$ \\
Female & $192(96)$ \\
Ethnicity & $8(4)$ \\
Caucasian & $120(60)$ \\
Latino-American & $77(38.5)$ \\
Facial aesthetics & $3(1.5)$ \\
Very important &
\end{tabular}

\subsection{Mandible}

The perception of mandibular spatial position showed a correct position in $17 \%$ of orthodontists, $19 \%$ of maxillofacial surgeons, 19\% of generic dentists, and 19\% of laypeople. A consistent agreement was recorded evaluating mandibular advancement, as follows: $80 \%$ of orthodontists, $76.5 \%$ of maxillofacial surgeons, $78.5 \%$ of generic dentists, and $69 \%$ of laypeople. The perception of mandibular position did not show a statistically significant difference among the groups $(p>0.05)$. All the categories recognized the alterations of the lower facial third as an important component of the skeletal malformation, but most of generic dentists (56\%) and laypeople $(63.5 \%)$ evaluated the mandibular advancement as the only component of skeletal class III deformity. A prominent chin was recorded in $74 \%$ of orthodontists, $50.5 \%$ of maxillofacial surgeons, $69.5 \%$ of generic dentists, and $67 \%$ of laypeople, with a statistically significant difference among the groups $(p<0.05)$.

\subsection{Zygomatic Area}

A flat zygomatic area was recorded in $76.5 \%$ of orthodontists, $71.5 \%$ of maxillofacial surgeons, $64.5 \%$ of generic dentists, and $66 \%$ of laypeople. A normal zygomatic area was recorded in $20.5 \%$ of orthodontists, $26.5 \%$ of maxillofacial surgeons, $29 \%$ of generic dentists, and $21.5 \%$ of laypeople. The perception of the zygomatic area showed a statistically significant difference among the groups $(p<0.01)$.

\subsection{Lip Perception}

Soft tissue assessment showed no statistically significant difference among the groups $(p>0.05)$. An alteration of lips harmony with an advanced lower lip in association to a retruded upper lip was identified by $27.5 \%$ of orthodontists, $38 \%$ of maxillofacial surgeons, $30.5 \%$ of generic dentists, and $23 \%$ of laypeople. A retruded upper lip without an advanced lower lip was recorded by $43 \%$ of orthodontists, $25 \%$ of maxillofacial surgeons, $29 \%$ of generic dentists, and $32.5 \%$ of laypeople.

\subsection{Asymmetric Perception}

Chin deviation was recorded by orthodontists (88\%), maxillofacial surgeons (86\%), generic dentists $(73.5 \%)$, and laypeople $(54.5 \%)$, with a statistically significant difference among the groups $(p<0.01)$.

Table 2 reported the bivariate comparison among the investigated groups. 
Table 2. Bivariate comparison among the investigated groups.

\begin{tabular}{|c|c|c|c|c|c|}
\hline & Orthodontists & General Dentists & Maxillofacial Surgeons & Laypeople & $p$-Value \\
\hline $\begin{array}{l}\text { Maxilla } \\
\text { 1. Correct position } \\
\text { 2. Advancement } \\
\text { 3. Retrusion }\end{array}$ & $\begin{array}{c}42(21) \\
2(1) \\
156(78)\end{array}$ & $\begin{array}{c}58(29) \\
20(10) \\
122(61)\end{array}$ & $\begin{array}{l}37(18.5) \\
31(15.5) \\
132(66)\end{array}$ & $\begin{array}{c}55(27.5) \\
47(23.5) \\
98(49)\end{array}$ & $<0.01$ \\
\hline $\begin{array}{l}\text { Mandible } \\
\text { 1. Correct position } \\
\text { 2. Advancement } \\
\text { 3. Retrusion }\end{array}$ & $\begin{array}{c}34(17) \\
160(80) \\
6(3)\end{array}$ & $\begin{array}{c}38(19) \\
157(78.5) \\
5(2.5) \\
\end{array}$ & $\begin{array}{c}38(19) \\
153(76.5) \\
9(4.5)\end{array}$ & $\begin{array}{l}38(19) \\
138(69) \\
24(12)\end{array}$ & $>0.05$ \\
\hline $\begin{array}{l}\text { Chin } \\
\text { 1. Normal } \\
\text { 2. Prominent } \\
\text { 3. Flat }\end{array}$ & $\begin{array}{c}42(21) \\
148(74) \\
10(5)\end{array}$ & $\begin{array}{c}50(25) \\
139(69.5) \\
11(5.5)\end{array}$ & $\begin{array}{c}89(44.5) \\
101(50.5) \\
10(5)\end{array}$ & $\begin{array}{c}44(22) \\
134(67) \\
22(11)\end{array}$ & $<0.05$ \\
\hline $\begin{array}{l}\text { Zygomatic area } \\
\text { 1. Flat } \\
\text { 2. Normal } \\
\text { 3. Prominent }\end{array}$ & $\begin{array}{c}153(76.5) \\
41(20.5) \\
6(3)\end{array}$ & $\begin{array}{c}129(64.5) \\
58(29) \\
13(6.5)\end{array}$ & $\begin{array}{c}143(71.5) \\
53(26.5) \\
4(2)\end{array}$ & $\begin{array}{l}132(66) \\
43(21.5) \\
25(12.5)\end{array}$ & $<0.01$ \\
\hline $\begin{array}{l}\text { Lip } \\
\text { 1. Retroposition of upper lip } \\
\text { 2. Advancement of lower lip } \\
\text { 3. No lip alteration }\end{array}$ & $\begin{array}{c}86(43) \\
55(27.5) \\
59(29.5)\end{array}$ & $\begin{array}{c}58(29) \\
61(30.5) \\
81(40.5)\end{array}$ & $\begin{array}{l}50(25) \\
76(38) \\
74(37)\end{array}$ & $\begin{array}{c}65(32.5) \\
46(23) \\
89(44.5)\end{array}$ & $>0.05$ \\
\hline $\begin{array}{l}\text { Chin asymmetry } \\
\text { 1. Centered } \\
\text { 2. Deviation }\end{array}$ & $\begin{array}{c}24(12) \\
176(88)\end{array}$ & $\begin{array}{c}53(26.5) \\
147(73.5)\end{array}$ & $\begin{array}{c}28(14) \\
172(86)\end{array}$ & $\begin{array}{c}91(45.5) \\
109(54.5)\end{array}$ & $<0.01$ \\
\hline
\end{tabular}

Statistically significant results were in bold.

\section{Discussion}

This study aimed to evaluate the perception of maxillary position and facial aesthetics in patients with class III malocclusion by comparing the opinion of orthodontists, maxillofacial surgeons, general dentists, and lay people.

The perception of facial aesthetics is a complex topic due to its subjective nature. It can be influenced by several factors, including education, age, sex, socioeconomic status, individual preferences, and multimedia sources, such as internet, social networks, and television [5]. However, severe deformities of class III patients are easy to recognize, and the concave profile is often negatively perceived by all examiners [3]. To date, the anteroposterior position of the maxilla has been extensively shown as a contributing factor to facial profile and aesthetics $[4,12]$.

The initial hypothesis of a different perception about the altered skeletal components of the class III malocclusion was confirmed by this survey, especially for the maxillary area. A significantly different evaluation was recorded among the observers in terms of maxillary position. Most of the specialized categories (orthodontists, generic dentists, and maxillofacial surgeons) assessed a sagittal retrusion of the maxilla, but only orthodontists and maxillofacial surgeons recognized that the alteration of the middle facial third is an important component of the skeletal class III malocclusion. These results agree with Alrbata and colleagues who showed that orthodontists are more sensitive in perceiving maxillary retrusion than other categories [13]. Probably, orthodontists pay more attention to maxillary development to intercept a skeletal class III malocclusion already in the early stages of growth [13]. Furthermore, both orthodontists and maxillofacial surgeons had to conform their aesthetic canons with the new preferences of a more protruded facial profile; therefore, they usually focus on jaw retrusion [15].

The significant difference in the middle facial third was also recorded for the perception of the zygomatic area. Orthodontists and maxillofacial surgeons evaluated a flat cheekbone contour in most of the class III patients. According to these results, Fenga and 
colleagues also reported that orthodontists perceive the less attractive zygomatic region than non-specialists, assessing an aging appearance of class III patients [16].

The perception of the mandibular position did not show a statistically significant difference among the different groups: $80 \%$ of orthodontists, $76.5 \%$ of maxillofacial surgeons, $78.5 \%$ of general dentists, and $69 \%$ of laypeople perceived the position of the jaw as protruded. However, in this study most of generic dentists and laypeople evaluated the mandibular advancement as the only component of the skeletal class III discrepancy. According to these results, several studies reported that an alteration in the lower facial third is more immediately perceived $[13,17,18]$. Johnston and colleagues showed that subjects with skeletal prognathism and vertical excess of growth are considered less attractive than subjects with normal face height, needing more efficient therapies [19].

In cases of prognathism, in addition to the mandibular protrusion, it is important to evaluate the chin prominence, because it can influence the perception of lower facial harmony $[20,21]$. In this study, the perception of chin position showed a statistically significant difference among the observers. Orthodontists have perceived the chin prominence more than other groups, as they probably are more sensitive in their judgment due to their training. Their assessments are based more on objective guidelines and ideal relationships, unlike the laity who are influenced by the culture of beauty $[17,22,23]$. In the last century, a prominent chin is considered an attractive male characteristic, especially in association with large, prominent lips [23-27].

The sagittal perception of class III profile is often strictly related to the frontal evaluation of the facial asymmetry. In this study, the recognition of skeletal asymmetry showed significant differences among the observers. Orthodontists and maxillofacial surgeons managed to identify the chin deviation better. According to these results, Barbosa and colleagues reported that the higher the degree of mandibular deviation is, the worse the scores assigned to facial aesthetics are, showing that maxillofacial surgeons were more sensitive to detect the presence of asymmetries compared to orthodontists and laymen [28].

In addition to the skeletal deformity, soft tissue assessment also assumes a fundamental role. In class III malocclusions with a prognathic profile, an everted lower lip with a smaller upward movement of mouth corners was recognized [29]. Although the lips position can also influence facial perception, no statistically significant differences among the observers were recorded in this study [30,31].

The study sample could limit the study. Caucasian respondents aged 20-30 may be influenced by their socioeconomic status and social media aesthetic patterns developed in the last few years.

In conclusion, this study highlighted that the four groups of participants had different perceptions of facial harmony, especially in the middle facial third. Orthodontists and maxillofacial surgeons were better able to assess maxillary retrusion in class III patients.

Author Contributions: Conceptualization, S.B., F.A., D.M., F.D. and A.G.; methodology S.B., F.A., D.M. and F.D.; investigation, F.A., D.M., F.D. and A.A.; resources, S.B. and F.B.; data curation, S.B.; writing-original draft preparation, S.B., F.A., D.M. and F.D.; writing-review and editing, S.B., F.A., D.M., F.D., F.B. and A.A.; visualization, A.G.; supervision, A.G.; project administration, S.B., F.A., D.M., F.D., F.B., A.A. and A.G. All authors have read and agreed to the published version of the manuscript.

Funding: This research received no external funding.

Institutional Review Board Statement: The study was conducted according to the guidelines of the Declaration of Helsinki and approved by the regional ethical review board, reference for the Magna Graecia University of Catanzaro, Catanzaro, Italy.

Informed Consent Statement: Informed consent was obtained from all subjects involved in the study. Written informed consent has been obtained from the patient to publish this paper.

Data Availability Statement: The data presented in this study are available on request from the corresponding author. The data are not publicly available due to privacy restrictions. 
Conflicts of Interest: The authors declare no conflict of interest.

\section{References}

1. Wei, H.; Liu, Z.; Zang, J.; Wang, X. Surgery-first/early-orthognathic approach may yield poorer postoperative stability than conventional orthodontics-first approach: A systematic review and meta-analysis. Oral Surg. Oral Med. Oral Pathol. Oral Radiol. 2018, 126, 107-116. [CrossRef]

2. Yao, K.; Zhu, G.; Chen, M.; Zhang, B.; Wu, Y.; Li, P. Effect of surgery-first orthognathic approach on oral health-related quality of life. Angle Orthod. 2020, 90, 723-733. [CrossRef] [PubMed]

3. Cassetta, M.; Guarnieri, R.; Mezio, M.; Altieri, F.; Brandetti, G.; Padalino, G.; Di Giorgio, R.; Barbato, E. Comparision of profile macro-estethic perception among orthodontists, dentistry students, orthodontic patients and surgical orthodontic patients. J. Clin. Exp. Dent. 2020, 12, e1109-e1116. [CrossRef]

4. Imani, M.M.; Sanei, E.; Niaki, E.A.; Shahroudi, A.S. Esthetic preferences of orthodontists, oral surgeons, and laypersons for Persian facial profiles. Am. J. Orthod. Dentofac. Orthop. 2018, 154, 412-420. [CrossRef]

5. Suphatheerawatr, T.; Chamnannidiadha, N. Perceived treatment need in patients with different facial profiles. J. World Fed. Orthod. 2020, 9, 75-79. [CrossRef] [PubMed]

6. Barone, S.; Morice, A.; Picard, A.; Giudice, A. Surgery-first orthognathic approach vs conventional orthognathic approach: A systematic review of systematic reviews. J. Stomatol. Oral Maxillofac. Surg. 2021, 122, 162-172. [CrossRef]

7. Tseng, Y.C.; Pan, C.Y.; Chou, S.T.; Liao, C.Y.; Lai, S.T.; Chen, C.M.; Chang, H.P.; Yang, Y.H. Treatment of adult Class III malocclusions with orthodontic therapy or orthognathic surgery: Receiver operating characteristic analysis. Am. J. Orthod. Dentofac. Orthop. 2011, 139, e485-e493. [CrossRef]

8. Staudt, C.B.; Kiliaridis, S. Different skeletal types underlying Class III malocclusion in a random population. Am. J. Orthod. Dentofac. Orthop. 2009, 136, 715-721. [CrossRef]

9. Ellis, E., 3rd; McNamara, J.A., Jr. Components of adult Class III malocclusion. J. Oral Maxillofac. Surg. 1984, 42, 295-305. [CrossRef]

10. Zere, E.; Chaudhari, P.K.; Sharan, J.; Dhingra, K.; Tiwari, N. Developing Class III malocclusions: Challenges and solutions. Clin. Cosmet. Investig. Dent. 2018, 10, 99-116. [CrossRef] [PubMed]

11. Haraguchi, S.; Takada, K.; Yasuda, Y. Facial asymmetry in subjects with skeletal Class III deformity. Angle Orthod. 2002, 72, 28-35. [CrossRef]

12. Pithon, M.M.; Lacerda-Santos, R.; Oliveira, D.L.; Alves, J.V.; Britto, J.P.; Souza Eda, S.; Alves, L.P.; Barbosa, G.; Coqueiro Rda, S.; Santos, A.F. Esthetic perception of facial profile after treatment with the Thurow Appliance. Braz. Oral Res. 2015, 29, 1-6. [CrossRef]

13. Alrbata, R.H.; Alfaqih, A.K.; Almhaidat, M.R.; Al-Tarawneh, A.M. Thresholds of Abnormality Perception in Facial Esthetics among Laypersons and Dental Professionals: Profile Esthetics. Int. J. Dent. 2020, 2020, 2068961. [CrossRef] [PubMed]

14. Li, B.; Shen, S.; Jiang, W.; Li, J.; Jiang, T.; Xia, J.J.; Shen, S.G.; Wang, X. A new approach of splint-less orthognathic surgery using a personalized orthognathic surgical guide system: A preliminary study. Int. J. Oral Maxillofac. Surg. 2017, 46, 1298-1305. [CrossRef] [PubMed]

15. Mousavi, S.M.; Saeidi Ghorani, P.; Deilamani, A.; Rakhshan, V. Effects of laterality on esthetic preferences of orthodontists, maxillofacial surgeons, and laypeople regarding the lip position and facial convexity: A psychometric clinical trial. Oral Maxillofac. Surg. 2019, 23, 439-451. [CrossRef]

16. Feng, J.; Yu, H.; Yin, Y.; Yan, Y.; Wang, Z.; Bai, D.; Han, X. Esthetic evaluation of facial cheek volume: A study using 3D stereophotogrammetry. Angle Orthod. 2019, 89, 129-137. [CrossRef] [PubMed]

17. Abu Arqoub, S.H.; Al-Khateeb, S.N. Perception of facial profile attractiveness of different antero-posterior and vertical proportions. Eur. J. Orthod. 2011, 33, 103-111. [CrossRef] [PubMed]

18. De Smit, A.; Dermaut, L. Soft-tissue profile preference. Am. J. Orthod. 1984, 86, 67-73. [CrossRef]

19. Johnston, D.J.; Hunt, O.; Johnston, C.D.; Burden, D.J.; Stevenson, M.; Hepper, P. The influence of lower face vertical proportion on facial attractiveness. Eur. J. Orthod. 2005, 27, 349-354. [CrossRef]

20. Sainath, M.C.; Preeti, R. Quantitative Eevaluation of Influence of Hard Tissue Chin Prominence on Perceived Normal Soft Tissue Facial Profile. Available online: http://www.ejournal-tnmgrmu.ac.in/index.php/surgery/article/view/11666 (accessed on 14 July 2021).

21. Abadi, M.; Pour, O.B. Genioplasty. Facial Plast. Surg. 2015, 31, 513-522. [CrossRef]

22. Yin, L.; Jiang, M.; Chen, W.; Smales, R.J.; Wang, Q.; Tang, L. Differences in facial profile and dental esthetic perceptions between young adults and orthodontists. Am. J. Orthod. Dentofac. Orthop. 2014, 145, 750-756. [CrossRef]

23. Fastuca, R.; Campobasso, A.; Zecca, P.A.; Caprioglio, A. 3D facial soft tissue changes after rapid maxillary expansion on primary teeth: A randomized clinical trial. Orthod. Craniofac. Res. 2018, 21, 140-145. [CrossRef]

24. Czarnecki, S.T.; Nanda, R.S.; Currier, G.F. Perceptions of a balanced facial profile. Am. J. Orthod. Dentofac. Orthop. 1993, 104, 180-187. [CrossRef]

25. Michiels, G.; Sather, A.H. Determinants of facial attractiveness in a sample of white women. Int. J. Adult Orthodon Orthognath Surg. 1994, 9, 95-103. [PubMed] 
26. Johnston, C.; Hunt, O.; Burden, D.; Stevenson, M.; Hepper, P. The influence of mandibular prominence on facial attractiveness. Eur. J. Orthod. 2005, 27, 129-133. [CrossRef]

27. Modarai, F.; Donaldson, J.C.; Naini, F.B. The influence of lower lip position on the perceived attractiveness of chin prominence. Angle Orthod. 2013, 83, 795-800. [CrossRef]

28. De Carvalho Barbosa, P.B.; Santos, P.L.; De Carli, J.P.; Luiz de Freitas, P.H.; Pithon, M.M.; Paranhos, L.R. Aesthetic facial perception and need for intervention in laterognathism in women of different ethnicities. J. Cranio-Maxillofac. Surg. 2017, 45, 1600-1606. [CrossRef]

29. Islam, R.; Kitahara, T.; Naher, L.; Hara, A.; Nakata, S. Lip Morphology Changes Following Orthognathic Surgery for Class III Malocclusion. Angle Orthod. 2010, 80, 344-353. [CrossRef] [PubMed]

30. Arnett, G.W.; Bergman, R.T. Facial keys to orthodontic diagnosis and treatment planning-Part II. Am. J. Orthod. Dentofac. Orthop. 1993, 103, 395-411. [CrossRef]

31. Johnson, E.K.; Fields, H.W., Jr.; Beck, F.M.; Firestone, A.R.; Rosenstiel, S.F. Role of facial attractiveness in patients with slight-toborderline treatment need according to the Aesthetic Component of the Index of Orthodontic Treatment Need as judged by eye tracking. Am. J. Orthod. Dentofac. Orthop. 2017, 151, 297-310. [CrossRef] [PubMed] 